\title{
Anmerkung zur Verfügung des Preußischen Finanzministers vom 11. Juni 1928
}

\author{
Christian Christiani*
}

\begin{abstract}
„Mitnichten wird hier dem Nachfahren des Hauses mit den beanstandeten Bildbeschreibungen Geldgier oder die Bereicherung auf Kosten des Steuerzahlers nachgesagt, sondern lediglich auf einen scheinbar historisch in Vergessenheit geratenen Verkauf von Kunstgegenständen im Rahmen der Vermögensauseinandersetzungen mit dem Preußischen Staat nach Abdankung des Preußischen Monarchen und Deutschen Kaisers aufmerksam gemacht. “1
\end{abstract}

- Die amtliche Aktenabschrift eines Verwaltungsvorgangs aus dem Büro des Direktors der Nationalgalerie Prof. Justi von 1928 ist Anlass für die Darstellung, die „Einschiffung nach Kythera" von Antoine Watteau und andere Kunstobjekte seien bereits 1926 / 1927 vom Preußischen Staat angekauft und bezahlt worden, bevor sie dann 1983 erneut von Bund, Land Berlin und den neu gegründeten Freunden der Preußischen Schlösser und Gärten e.V. für die Berliner Schlösserverwaltung angekauft wurden².

Das Dokument ${ }^{3}$ wurde im Jahr 2007 im Zentralarchiv der Staatlichen Museen zu Berlin entdeckt und ist seitdem in Fachkreisen bekannt. Während der Teilung Berlins hatte sich diese Abschrift im Archiv der Nationalgalerie in Ost-Berlin befunden. Daher war das Dokument bei dem Ankauf der zwei Silberpokale von Jamnitzer und Petzolt durch das West-Berliner Kunstgewerbemuseum im Jahr 1963 und dem Ankauf der „Einschiffung“ für die West-Berliner Schlösserverwaltung im Jahr 1983 anscheinend nicht zugänglich.

Rechtsgrundlage für den Ankauf der "Einschiffung" und der Pokale ist das in der Preußischen Gesetzessammlung von 1926 abgedruckte "Gesetz über die Vermögensauseinandersetzung zwischen dem Preußischen Staate und den Mitgliedern des vormals regierenden Preußischen Königshauses vom 29.10.1926", in dem die Vermögensauseinandersetzung umfassend und abschließend geregelt wurde. Hierin wurde für die in dem Dokument von 1928 genannten Gegenstände folgende Regelung getroffen (Abänderungsvertrag vom 06.10.1926, Ziff. 8 c): „Das vormals regierende Königshaus verpflichtet sich, das Eigentum an den in Anlage B Abschnitt III Ziffer 1 bis 10 (...) bezeichneten und weiteren nach besonderem Verzeichnis bestimmten Kunstwerken auf Verlangen des Staates auf diesen zu übertragen; das Entgelt bestimmt ein gemeinsam ernannter Sachverständiger."

* Christian Christiani ist Rechtsanwalt in Berlin und hat im Verfahren vor dem LG Berlin (27 O 500/12) die Streitverkündeten vertreten.

$1 \quad$ LG Berlin, Urteil v. 13.11.2012 - 27 O 500/12.

2 Guido Hinterkeuser: Das Berliner Schloss - Die erhaltene Innenausstattung: Gemälde, Skulpturen, Dekorative Kunst, Gesellschaft Berliner Schloss (Hg.), Regensburg 2012, S. 56, 155; Stiftung Preußische Schlösser und Gärten (Hg.), Bestandskataloge der Kunstsammlungen, Französische Gemälde I, Berlin 2011, Kat. Nr. 6.

3 Akte I/NG/470 des Archivs der Staatlichen Museen zu Berlin.
Das Dokument ist eine Abschrift eines gesamten Verwaltungsvorgangs für die eigene Akte (Vorgangsnummer 1472) der Nationalgalerie. Ausweislich dieses Dokuments informierte das Preußische Finanzministerium (durch den Staatssekretär Schleusener) zunächst das Ministerium für Wissenschaft, Kunst und Volksbildung, und dieses dann den Direktor der Staatlichen Schlösser und Gärten, den Generaldirektor der Staatlichen Museen und den Direktor der Nationalgalerie über den Inhalt eines Erlasses des Preußischen Finanzministeriums vom 11. Juni 1928. Hiermit wurden die von dem Ankauf profitierenden staatlichen Behörden und Institutionen über den erfolgten Eigentumserwerb an den Kunstgegenständen informiert, damit sie die ihnen zufallenden Gegenstände in ihre Bestandsverzeichnisse aufnehmen konnten. Der Direktor der Nationalgalerie, Prof. Ludwig Justi, vermerkte schließlich handschriftlich mit seinem Namenskürzel („J." = Justi oder "D.D." = Der Direktor) am Ende der Abschrift des Verwaltungsvorgangs seine Anweisungen, die für die Nationalgalerie angekauften Werke aus der Liste in das Inventar der Nationalgalerie aufzunehmen, nämlich die „Paradebilder" von Franz Krüger und das im zweiten Weltkrieg zerstörte Gemälde „Überfall von Hochkirch" von Menzel. Die Inventarisierung wurde dann durch handschriftliche Einfügung der Inventarnummern am Rande des Dokuments neben der Liste der angekauften Kunstwerke vermerkt. Weitere Werke, die heute in der Alten Nationalgalerie ausgestellt sind - wie die "Prinzessinnengruppe" von Schadow - und deren Ankauf ebenfalls anscheinend nur durch dieses Dokument überliefert ist, gehörten damals noch zum Bestand des Berliner Schlosses.

Die Berliner Senatskanzlei - Kulturelle Angelegenheiten geht bisher davon aus, dass der Ankaufsvorgang von 1926 / 1927 nicht bewiesen sei und lässt den Vorgang daher seit längerer Zeit prüfen. 